\title{
Incidence of reversible amenorrhea in women with breast cancer undergoing adjuvant anthracycline-based chemotherapy with or without docetaxel
}

\author{
Martine Berliere*1, Florence Dalenc ${ }^{3}$, Nathalie Malingret ${ }^{1}$, Anita Vindevogel ${ }^{4}$, \\ Philippe Piette ${ }^{2}$, Henry Roche ${ }^{3}$, Jacques Donnez ${ }^{1}$, Michel Symann², \\ Joseph Kerger ${ }^{4}$ and Jean-Pascal Machiels ${ }^{2}$
}

Address: ${ }^{1}$ Gynecology, Breast Clinic, Cancer Center, Cliniques Universitaires St Luc, Brussels, Belgium, ${ }^{2}$ Oncology, Breast Clinic, Cancer Center, Cliniques Universitaires St Luc, Brussels, Belgium, ${ }^{3}$ Oncology, Institut Claudius Regaud, Toulouse, France and ${ }^{4}$ Oncology, Clinique Ste Elisabeth, Namur, Belgium

Email: Martine Berliere* - martine.berliere@gyne.ucl.ac.be; Florence Dalenc - Dalenc.Florence@claudiusregaud.fr; Nathalie Malingret - Nathalie.Malingret@hotmail.com; Anita Vindevogel - avindevoghel@ohr.be;

Philippe Piette - Philippe.Piette@onco.ucl.ac.be; Henry Roche - Roche.Henry@claudiusregaud.fr; Jacques Donnez - donnez@gyne.ucl.ac.be; Michel Symann - Michel.Symann@onco.ucl.ac.be; Joseph Kerger - jkerger@ohr.be; Jean-Pascal Machiels - Jean-Pascal.Machiels@onco.ucl.ac.be * Corresponding author

Published: 21 February 2008

BMC Cancer 2008, 8:56 doi:10.1/86/147|-2407-8-56
Received: 21 September 2007

Accepted: 21 February 2008

This article is available from: http://www.biomedcentral.com/I47I-2407/8/56

(C) 2008 Berliere et al; licensee BioMed Central Ltd.

This is an Open Access article distributed under the terms of the Creative Commons Attribution License (http://creativecommons.org/licenses/by/2.0), which permits unrestricted use, distribution, and reproduction in any medium, provided the original work is properly cited.

\begin{abstract}
Background: To determine the incidence of reversible amenorrhea in women with breast cancer undergoing adjuvant anthracycline-based chemotherapy with or without docetaxel.

Methods: We studied the incidence and duration of amenorrhea induced by two chemotherapy regimens: (i) 6 cycles of 5 -fluorouracil $500 \mathrm{mg} / \mathrm{m}^{2}$, epirubicin $100 \mathrm{mg} / \mathrm{m}^{2}$ and cyclophosphamide $500 \mathrm{mg} /$ $\mathrm{m}^{2}$ on day I every 3 weeks (6FEC) and (ii) 3 cycles of FEC 100 followed by 3 cycles of docetaxel $100 \mathrm{mg} /$ $\mathrm{m}^{2}$ on day I every 3 weeks (3FEC/3D). Reversible amenorrhea was defined as recovery of regular menses and, where available (IOI patients), premenopausal hormone values (luteinizing hormone (LH), folliclestimulating hormone (FSH) and estradiol) in the year following the end of chemotherapy.
\end{abstract}

Results: One hundred and fifty-four premenopausal patients were included: 84 treated with 6FEC and 70 with 3FEC/3D. The median age was 43.5 years (range: 28-58) in the 6FEC arm and 44 years (range: 2953 ) in the 3FEC/3D arm. Seventy-eight percent of patients were treated in the context of the PACS 0 I trial. The incidence of chemotherapy-induced amenorrhea at the end of chemotherapy was similar in the two groups: $93 \%$ in the $6 \mathrm{FEC}$ arm and $92.8 \%$ in the 3FEC/3D arm. However, in the year following the end of chemotherapy, more patients recovered menses in the 3FEC/3D arm than in the 6FEC arm: 35.5 $\%$ versus $23.7 \%(p=0.019)$. Among the I0I patients for whom hormone values were available, $43 \%$ in the $3 \mathrm{FEC} / 3 \mathrm{D}$ arm and $29 \%$ in the 6FEC arm showed premenopausal levels one year after the end of chemotherapy $(p<0.01)$. In the 3FEC/3D group, there was a statistically significant advantage in diseasefree survival (DFS) for patients who were still amenorrheic after one year, compared to patients who had recovered regular menses $(p=0.0017)$.

Conclusion: Our study suggests that 3FEC/3D treatment induces more reversible amenorrhea than 6FEC. The clinical relevance of these findings needs to be investigated further. 


\section{Background}

Adjuvant chemotherapy prolongs disease-free and overall survival of patients with breast cancer. In premenopausal women, cytotoxic chemotherapy can induce temporary or permanent ovarian dysfunction [1-4]. The incidence of chemotherapy-induced amenorrhea is directely related to age and varies with the type of chemotherapeutic agent used $[5,6]$, as well as its dose and schedule [1]. Data on ovarian function are widely available for certain regimens, such as cyclophosphamide, methotrexate and 5-fluorouracil (CMF) polychemotherapy [6,7] and anthracyclinebased treatments $[8,9]$, but fewer studies have been conducted on taxane-based regimens and they unfortunately show contradictory results [10-13]. Here, we report the results of a retrospective analysis evaluating the incidence of reversible amenorrhea in women with early-stage breast cancer undergoing adjuvant anthracycline-based chemotherapy with or without docetaxel.

\section{Methods}

\section{Patients and study design}

Between June 1997 and March 2000, 1999 patients from 83 French and Belgian cancer centers were included in the PACS 01 trial. This trial was designed to evaluate the impact of the sequential addition of docetaxel to anthracycline-based chemotherapy on the disease-free survival (DFS) of patients with node-positive operable breast cancer [7]. The design of the study is detailed in Figure 1. The first arm (6FEC) involved administration of 6 cycles of FEC 100 (5-fluorouracil $500 \mathrm{mg} / \mathrm{m}^{2}$, epirubicin $100 \mathrm{mg} /$ $\mathrm{m}^{2}$, and cyclophosphamide $500 \mathrm{mg} / \mathrm{m}^{2}$ ) on day 1 every 3 weeks, and the second arm (3FEC/3D), administration of 3 cycles of FEC 100 followed by 3 cycles of docetaxel 100 $\mathrm{mg} / \mathrm{m}^{2}$ on day 1 every 3 weeks.

Two Belgian centers (Cliniques Universitaires St Luc (UCL), Brussels, and Clinique Ste Elisabeth, Namur) and one French center (Institut Claudius Regaud, Toulouse) retrospectively studied a number of premenopausal patients $(\mathrm{n}=154)$ : 121 patients $(78 \%)$ included in the PACS 01 trial and 33 patients $(22 \%)$ treated with the same regimens after the PACS 01 inclusion period. These patients were followed clinically for menses recovery every 3 months. For 101 patients, hormone values were also available (luteinizing hormone (LH), follicle-stimulating hormone (FSH) and estradiol). A minimum of two tests were performed at 3-monthly intervals in the year following the end of chemotherapy.

Study of amenorrhea was not an endpoint of the PACS 01 trial. Clinicians had to report patient status (amenorrheic or not) at the end of the study, but no follow-up of menopausal status was required.
In the centers ( 2 Belgian, 1 French) conducting the retrospective study, clinicians were specifically interested in investigating amenorrhea and collected clinical and (for 101 women) biological data. Since a total of 1211 premenopausal patients (598 in the 6FEC arm and 613 in the 3FEC/3D arm) were enrolled in the PACS 01 trial, our series of 154 patients ( 121 from the PCAS 01 trial +33 outside the trial) effectively represents $10 \%$ of all premenopausal patients included in the PACS 01 trial.

The PACS 01 study was approved by the institutional ethical committees of all the centers involved. For blood tests, informed consent was obtained from patients in accordance with institutional guidelines.

The main objective of our retrospective study was to evaluate the incidence of reversible chemotherapy-induced amenorrhea in patients treated with 6FEC and 3FEC/3D (impact of sequential docetaxel on the rate of chemotherapy-related amenorrhea). Reversible amenorrhea was defined as recovery of regular menses and, where available (101 patients), premenopausal LH, FSH and 17-betaestradiol values in the year following the last chemotherapy infusion. Premenopausal hormone concentrations were defined by our laboratory as $\mathrm{LH}<17.1 \mathrm{mIU} / \mathrm{ml}$, FSH $<45.7 \mathrm{mIU} / \mathrm{ml}$, and 17-beta-estradiol $>50 \mathrm{pg} / \mathrm{ml}$.

Menopausal status was defined according to World Health Organization recommendations, which regard amenorrhea lasting 12 months as indicative of the menopause [14]. It is important to note that, in breast cancer, criteria for identifying women as postmenopausal vary between trials and research groups.

\section{Statistical analysis}

Kaplan-Meier analyses were used to calculate DFS probabilities. The log-rank test was used for DFS comparisons. Patient disease characteristics and differences in amenorrhea rates were compared using the chi-square test. A pvalue $<0.05$ was considered statistically significant.

\section{Results}

\section{Patient characteristics}

One hundred and fifty-four premenopausal patients were included: 84 treated with 6FEC and 70 with 3FEC/3D. Patient characteristics are described in Table 1. The median age was 43.5 years (range: $28-58$ ) in the 6FEC arm and 44 years (range: $29-53$ ) in the $3 F E C / 3 D$ arm. The classic prognostic factors for early breast cancer were also well balanced between the two groups. Seventy-eight percent of patients were treated in the context of the PACS 01 trial. 
Stratified according to:

1. Center

2. Age: $<$ or $\geq 50$

3. $N: 1-3 ;>4$

\section{SURGERY}

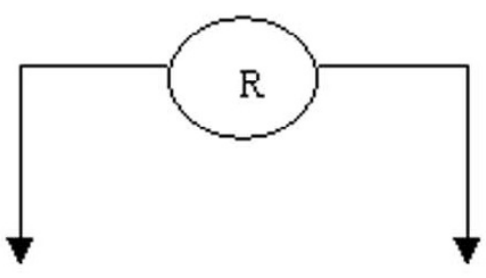

\section{FEC 100: $\operatorname{arm} A$}

\section{fluorouracil $500 \mathrm{mg} / \mathrm{m}^{2} \mathrm{~d} 1$}

epirubicin $100 \mathrm{mg} / \mathrm{m}^{2} \mathrm{~d} 1$

cyclophosphamide $500 \mathrm{mg} / \mathrm{m}^{2} \mathrm{~d} 1$

6 cycles every 21 days

\section{FEC 100 / 3 docetaxel: arm B}

3 cycles of FEC 100 every

21 days followed by

3 cycles of docetaxel $100 \mathrm{mg} / \mathrm{m}^{2}$

d1 every 21 days

$\rightarrow$ radiother apy delivered within 4 weeks of the last chemotherapy cycle

$\rightarrow$ tamoxifen $20 \mathrm{mg} /$ day for 5 years prescribed to hormone receptor-positive postmenopausal

women after chemotherapy, then after amendment to all hormone receptor-positive.

Figure I

Design of the PACS OI study.

\section{Amenorrhea incidence}

The incidence of chemotherapy-induced amenorrhea at the end of treatment was not found to be statistically different between the two groups: $93 \%$ in the 6 FEC arm and $92.5 \%$ in the $3 \mathrm{FEC} / 3 \mathrm{D}$ arm (Table 2). However, in the year following the end of chemotherapy, more patients recovered regular menses in the $3 \mathrm{FEC} / 3 \mathrm{D}$ arm than the 6FEC arm: 25 out of 70 (36.5\%) versus 20 out of 84 (23.7
$\%$ ) ( $\mathrm{p}<0.019$ ). Among the 101 patients for whom hormone values were also available, more patients recovered premenopausal hormone levels in the 3FEC/3D arm than the 6FEC arm within a year after the end of chemotherapy $(42 \%(18 / 42)$ versus $29 \%(17 / 59))(\mathrm{p}<0.01)$.

Premenopausal patients were also stratified according to age ( $<$ or $\geq 40$ years). The incidence of reversible chemo- 
Table I: Patient characteristics

\begin{tabular}{|c|c|c|}
\hline & 6 FEC 100 & 3 FEC/3D \\
\hline Total number of patients (154) & 84 & 70 \\
\hline Median age (range) & $43.5(28-58)$ & $4429-53)$ \\
\hline Patients $<40$ years $(n=39)$ & $18(21.5 \%)$ & $21(30 \%)$ \\
\hline Patients $\geq 40$ years $(n=115)$ & $66(78 \%)$ & $49(70 \%)(p=0.08)$ \\
\hline \multicolumn{3}{|l|}{ Hormone receptor status } \\
\hline Positive (ER and/or PR) & $61(72.6 \%)$ & $53(75.9 \%)$ \\
\hline Negative (ER and PR) & $23(27.4 \%)$ & $17(24.1 \%)$ \\
\hline ER positive & 60 (7I. $4 \%)$ & $52(74.2 \%)$ \\
\hline ER negative & $24(28.5 \%)$ & $18(25.7 \%)$ \\
\hline PR positive & $50(59.5 \%)$ & $44(62.8 \%)$ \\
\hline PR negative & $34(40.4 \%)$ & $26(37.1 \%)$ \\
\hline \multicolumn{3}{|l|}{ Median tumor size (range) } \\
\hline \multicolumn{3}{|l|}{ Tumor grade } \\
\hline 1 & $8(9.5 \%)$ & $6(8.6 \%)$ \\
\hline II & $34(40.5 \%)$ & $30(42.8 \%)$ \\
\hline III & $42(50 \%)$ & $34(48.6 \%)$ \\
\hline \multicolumn{3}{|l|}{ Number of metastatic lymph nodes } \\
\hline$<4$ & $66(78.6 \%)$ & $53(75.9 \%)$ \\
\hline$\geq 4$ & 18 (2I.4\%) & $17(24.1 \%)$ \\
\hline \multicolumn{3}{|l|}{ Tumor size } \\
\hline TI & $25(29.7 \%)$ & $21(30 \%)$ \\
\hline $\mathrm{T} 2$ & $50(59.5 \%)$ & $42(60 \%)$ \\
\hline T3 & $9(10.8 \%)$ & $7(10 \%)$ \\
\hline
\end{tabular}

ER: estrogen receptor; PR: progesterone receptor $(p$-value never $<0.05)$

therapy-induced amenorrhea was found to be similar between the two chemotherapy regimens for patients under 40 years of age $(72 \%(13 / 18)$ with 6 FEC versus $71.4 \%$ (15/21) with 3FEC/3D). For patients over 40 years of age, however, statistically more recovered regular menses in the 3FEC/3D arm than the 6FEC arm: 10 out of 49 $(20 \%)$ and 7 out of $66(10.6 \%)$ respectively $(\mathrm{p}<0.025)$.
Clinically reversible amenorrhea and disease-free survival At the time of analysis, the median follow-up for the whole group was 79 months (96 months for 6FEC and 63 for 3FEC/3D). For the whole population, DFS was significantly better in patients with persistent amenorrhea after one year compared to those who had recovered menses ( $p$ $=0.0017$ ) (data not shown). In the 6FEC group, there was no statistical difference between patients with or without persistent amenorrhea $(\mathrm{p}=0.36)$. By contrast, in the $3 \mathrm{FEC} / 3 \mathrm{D}$ group, there was a statistically significant advan-

Table 2: Incidence of amenorrhea

\begin{tabular}{|c|c|c|}
\hline & 6FEC 100 & 3FEC/3D \\
\hline Amenorrhea at the end of chemotherapy & $78(93 \%)$ & $65(92.8 \%)$ \\
\hline \multicolumn{3}{|l|}{ Clinically reversible amenorrhea $(n=154)$} \\
\hline Total population** & $20 / 84(23.7 \%)$ & $25 / 70(35.5 \%)$ \\
\hline Patients < 40 years $(39)$ & $13 / 18(72 \%)$ & $15 / 2 \mid(7 \mid .4 \%)$ \\
\hline Patients $\geq 40$ years $(115)^{* *}$ & $7 / 66(10.5 \%)$ & $10 / 49(20.5 \%)$ \\
\hline \multicolumn{3}{|l|}{ Recovery of premenopausal hormone values * } \\
\hline Total population $(\mathrm{n}=10 \mathrm{I})^{* *}$ & $18 / 59(29 \%)$ & $18 / 42(42 \%)$ \\
\hline Patients $<40$ years $(3 \mathrm{I})$ & $11 / 15(73.3 \%)$ & $12 / 16(75 \%)$ \\
\hline Patients $\geq 40$ years $(70)^{* *}$ & $6 / 42(14 \%)$ & $6 / 28(21.4 \%)$ \\
\hline \multicolumn{3}{|c|}{ Clinically reversible amenorrhea. No hormone values available $(n=53)$} \\
\hline Patients < 40 years $(8)$ & $2 / 3(66 \%)$ & $3 / 5(60 \%)$ \\
\hline Patients $\geq 40$ years $(45)^{* *}$ & $\mathrm{I} / 24(4 \%)$ & $4 / 21(19 \%)$ \\
\hline
\end{tabular}

*within a year after the end of chemotherapy

$* * p<0.05$, chi-square 
tage in DFS for patients who were still amenorrheic after one year, compared to patients who had recovered regular menses $(\mathrm{p}=0.0001)$ (Figure 2).

When statistical analysis was restricted to patients whose tumors expressed ER and/or PR, the same tendency was observed in the 3FEC/3D group: a statistically significant advantage for patients who were still amenorrheic after one year, compared to those who had recovered premenopausal ovarian function ( $\mathrm{p}<0.002)$ (Figure 3$)$. By contrast, in the 6FEC group, there was no statistical difference between patients with or without persistent amenorrhea $(\mathrm{p}=0.22)$.

In the small subgroup of patients with ER- and PR-negative tumors, no statistically advantage in DFS was observed in patients still amenorrheic at one year $(\mathrm{p}=$ 0.817 in the 6FEC arm and $\mathrm{p}=0.445$ in the 3FEC/3D arm). But this subgroup was too small to allow valid statistical analysis.

\section{Discussion}

The rate of chemotherapy-related amenorrhea varies according to the diagnostic criteria adopted and the duration of follow-up [1], but inconsistencies exist in the way it is reported. Some authors report the incidence of amen- orrhea immediately upon completion of chemotherapy, while others select various time points after the start and end of chemotherapy $[1,5]$. The time point most commonly encountered in the literature is 12 months after the end of chemotherapy [2]. Chemotherapy-related amenorrhea is generally linked to the patient's age as well as treatment protocol $[1,2,7-9,11-13]$. In our study, in women over 40 years of age, reversible amenorrhea was more frequently observed in patients treated with $3 \mathrm{FEC} / 3 \mathrm{D}$ than 6FEC. Moreover, our data suggest that DFS was better in patients with persistent amenorrhea in the 3FEC/3D group.

Chemotherapy-related amenorrhea depends considerably on the regimen used. Cyclophosphamide is a cytotoxic agent that has been extensively investigated and is widely known to induce amenorrhea [6,7]. According to Goldhirsh [7], $61 \%$ of women under 40 years of age experienced amenorrhea after receiving CMF, while $95 \%$ of women over 40 became amenorrheic after this regimen. Amenorrhea associated with anthracycline-based therapy nevertheless shows significant variation from study to study. Bines et al [1] found a $35 \%$ amenorrhea rate with the 4-cycle AC regimen (adriamycin $60 \mathrm{mg} / \mathrm{m}^{2}$, cyclophosphamide $600 \mathrm{mg} / \mathrm{m}^{2}$, 4 courses every 3 weeks), Hortobagyi et al [8] $59 \%$ with the 6-cycle FAC regimen (5-

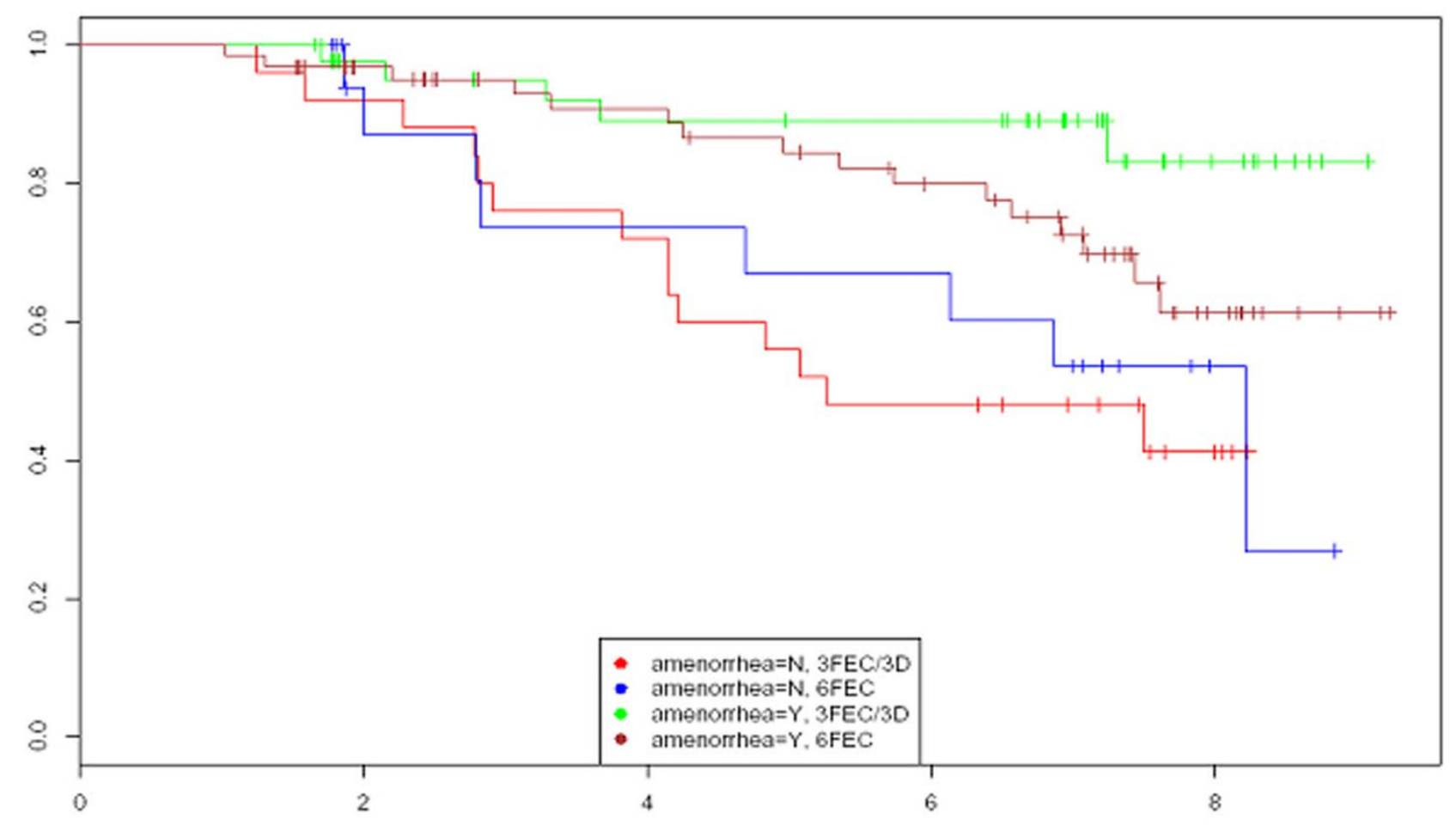

Figure 2

Kaplan Meier curves. 


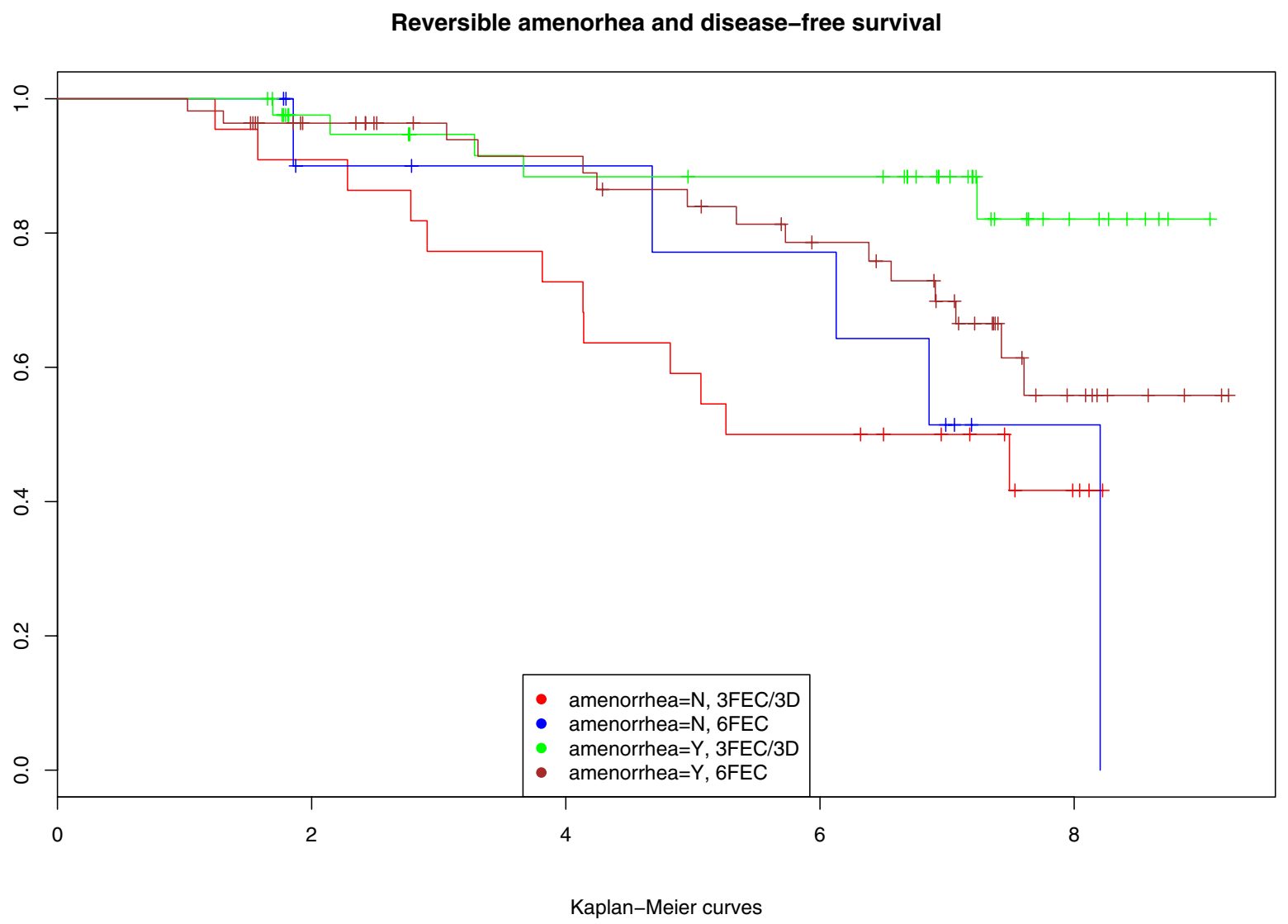

Figure 3

Reversible amenorrhea and disease-free survival.

fluorouracil $500 \mathrm{mg} / \mathrm{m}^{2}$, doxorubicin $50 \mathrm{mg} / \mathrm{m}^{2}$, cyclophosphamide $500 \mathrm{mg} / \mathrm{m}^{2}$ ), and Levine et al [9] $51 \%$ with the 6 -cycle CEF regimen (cyclophosphamide $75 \mathrm{mg} / \mathrm{m}^{2}$ orally on days 1 through 14 , epirubicin $60 \mathrm{mg} / \mathrm{m}^{2} \mathrm{IV}$ on days 1 and 8 , 5-fluorouracil $500 \mathrm{mg} / \mathrm{m}^{2}$ on days 1 and 8 ). The results observed in our study with 6FEC 100 are not different from those observed in the literature $[1-3,8,9]$.

There are fewer published results on taxane regimens and the are somewhat contradictory [11-13]. Moreover, some of the literature is reported in abstract form [15-18]. In the BCIRG 001 study $[15,16,18]$, 6TAC was compared to 6FAC (TAC: docetaxel $75 \mathrm{mg} / \mathrm{m}^{2}$, doxorubicin $50 \mathrm{mg} / \mathrm{m}^{2}$, cyclophosphamide $500 \mathrm{mg} / \mathrm{m}^{2}$; FAC: 5-fluorouracil 500 $\mathrm{mg} / \mathrm{m}^{2}$, doxorubicin $50 \mathrm{mg} / \mathrm{m}^{2}$, cyclophosphamide 500 $\left.\mathrm{mg} / \mathrm{m}^{2}\right)$. TAC gave better disease-free and overall survival than FAC, but increased the rate of amenorrhea (66\% versus $54 \%)(p=0.008)$ by contrast, in our study, the 3 FEC/
$3 \mathrm{D}$ regimen induced less definitive amenorrhea than the 6FEC 100 regimen. Unfortunately, the method and time of evaluation of amenorrhea were not reported.

In the study by Fornier, 166 very young patients were reviewed. All patients were treated with AC (doxorubicin at a dose of $60 \mathrm{mg} / \mathrm{m} 2+$ cyclophosphamide at a dose of $600 \mathrm{mg} / \mathrm{m} 2$ for 4 cycles followed by a taxane). The majority of patients were given AC followed by paclitaxel at a dose of $175 \mathrm{mg} / \mathrm{m} 2$ for 4 cycles adminitered at 2- or 3week intertreatment intervals.

Only 7 patients received docetaxel (100 mg/m2).

In this cohort, long-term amenorrhea was defined as the absence of menstruation $\geq 12$ months after the completion of all chemotherapy. No hormone values were available and the conclusions of this study were that addition 
of a taxane did not appear to produce a higher rate of chemotherapy-related amenorrhea, compared to historical controls.

In the study by Davis, 159 premenopausal patients were reviewed. As initial chemotherapy, 102 women received AC (doxorubicin/cyclophosphamide), 39 received CMF (cyclophosphamide/methotrexate/5-fluorouracil) and 18 received CAF (cyclophosphamide/doxorubicin/5-fluorouracil).

Following the initial regimen, 53 patients received additional adjuvant chemotherapy, generally with a taxane for 12 weeks (paclitaxel in 32 patients and docetaxel in 19 patients).

The conclusions of this study were similar to those of Fornier. Sequential addition of taxanes did not appear to increase the risk of chemotherapy-induced amenorrhea, when added to non-taxane regimens. Moreover, the author did not find any impact of the type of initial chemotherapy administered. The definition of chemotherapyrelated amenorrhea was the same as that used by Fornier and our team. As in Fornier's study, no hormone values were available.

More recently, Tham published a study involving 191 patients (158 patients $\leq 40$ years of age at the start of chemotherapy). The patients received 4 cycles of AC alone or followed by a taxane (there was no stratification between paclitaxel and docetaxel).

The definition of chemotherapy-related amenorrhea was a little different in this study. Indeed, it was defined as cessation of menses within 1 year of starting chemotherapy and lasting $\geq 6$ months.

As demonstrated in all these studies, age and type of chemotherapy regimen were independently related to the rate of chemotherapy-induced amenorrhea.

No hormone values were available.

In the subgroup of younger patients ( $\leq 40$ years), addition of a taxane resulted in a higher incidence of chemotherapy-related amenorrhea (61 versus $44 \%$ ). In women over 40 years of age, amenorrhea rates were high in both the group of AC alone and the group of AC followed by a taxane ( 81 versus $85 \%)$. No statistically significant difference was observed between the two groups.

However, in this study, the patients treated with a taxane received more chemotherapy cycles and this could have had an impact on the results.
In our study, women over 40 years of age were at much greater risk of developing definitive amenorrhea than those under 40, highlighting the importance of patient age $[19,20]$. Milan's regimen, using $6 \mathrm{CMF}$ with or without doxorubicin, resulted in an amenorrhea rate of $4 \%$ in women under 30 years of age, $50 \%$ in women aged between 36 and 40 years, $86 \%$ in women aged between 41 and 45 years, and $100 \%$ in women over 45 years of age [20]. Similar variations were observed with epirubicincontaining regimens $[8,9]$ and taxanes [11-13]. Our study has the advantage of providing hormone profiles of $2 / 3$ of the patients, but the limitations are similar to those encoutered, in other studies, i.e. the retrospective design and the small number of patients.

Whether or not induction of amenorrhea by cytotoxic chemotherapy is a prognostic factor in the treatment of premenopausal women is still controversial. A positive impact on DFS has been found by some [21-27], but not confirmed by others $[17,28]$. Del Mastro et al $[21]$ conducted a review of 13 studies involving 3929 patients undergoing CMF-based regimens, with follow-up ranging from 3 to 20 years. A statistically significant association was found between the development of chemotherapyrelated amenorrhea and DFS. In the majority of cases, overall survival was found to be associated with amenorrhea (in 3 out of 5 studies reviewed). In a study recently published by Parulekar [21], similar results were observed with intensive CEF (cyclophosphamide, epirubicin, fluorouracil) therapy, which induced a higher rate of amenorrhea than the classic CMF protocol, but overall survival was also better.

Another important question relates to the duration of amenorrhea. In Trial VI (study by the International Breast Cancer Study Group (IBCSG)), cessation of menses, even for a limited time period, appeared to be beneficial, especially in patients with ER-positive breast tumors. In this study [29], however, the greatest effect was observed in patients receiving suboptimal treatment with only three initial CMF courses. In the PACS 01 trial [10], a survival advantage in favor of the $3 \mathrm{FEC} / 3 \mathrm{D}$ arm was observed only for women aged over 50 years, but not for the younger population. The reason for this is unclear but the impact of reversible amenorrhea in this context needs to be investigated further, since our small retrospective analysis suggests that amenorrhea was correlated with DFS in the 3FEC/3D group.

In our population, $73 \%$ of patients received tamoxifen in the $6 \mathrm{FEC}$ arm, and $74 \%$ in the $3 \mathrm{FEC} / 3 \mathrm{D}$ arm. The ovarian stimulation effect of tamoxifen in premenopausal women is well documented [30], but its effects on the duration of chemotherapy-induced amenorrhea are not well defined or understood. In a study by Tham [13], tamoxifen was 
not shown to influence the incidence of amenorrhea, but the impact of tamoxifen on the hypothalamo-pituitary axis is complex and sequential administration of tamoxifen after chemotherapy does not simplify the data. It is therefore important to monitor a variety of hormonal tests to assess the consequences of sequential administration of antiestrogen treatment after chemotherapy.

Gonadal toxicity resulting from chemotherapy was first reported almost 60 years ago and the gonadotoxic effects of chemotherapeutic agents are well documented. Although the prevailing mechanisms are not fully understood, three clinical studies have suggested that chemotherapy induces apoptotic changes in pregranulosa cells that subsequently develop into follicles [31]. However, these findings have not yet been confirmed in human studies [3]. Chemotherapy also provokes a reduction in the number of available oocytes. These changes are similar to those observed in natural postmenopausal ovaries. This cytotoxic damage appears to be progressive and irreversible in the ovary, as jump cells are limited in number and cannot be regenerated [32,33].

\section{Conclusion}

Our retrospective study confirms that chemotherapyrelated amenorrhea is highly complex, requiring in-depth analysis, especially with the advent of new chemotherapeutic agents. A number of questions need to be elucidated in the coming years. Is achieving amenorrhea a desirable side effect? Is temporary amenorrhea as effective as definitive amenorrhea? What are the implications of endocrine treatment for patients who recover ovarian function? Is it necessary to propose ovarian function suppression associated with tamoxifen or aromatase inhibitors? Some of these questions are currently being addressed in large randomized trials (PERCHE (stopped), SOFT, TEXT). Besides the prognostic potential of reversible amenorrhea and therapeutic impact of the endocrine approach, other issues also need clarification. What are the implications of reversible amenorrhea on both sexual function and preservation of fertility potential? All these quesions are often a major concern for young premenopausal breast cancer patients. On the basis of our findings, we believe it is crucial to carefully monitor ovarian function after chemotherapy for at least 12 months following the end of treatment, with separate analysis of results in women with hormone-sensitive disease. The impact of reversible amenorrhea on prognosis needs to be investigated prospectively, and ovarian function followed clinically, as well as by means of biochemical testing (large randomized trials).

\section{Abbreviations}

$\mathrm{ER}$, estrogen receptor; $\mathrm{PR}$, progesterone receptor; $\mathrm{N}$, no; $\mathrm{Y}$, yes

\section{Competing interests}

HR has been a consultant with Sanofi-Aventis in the past five years. The rest of the authors have no competing interests to declare.

\section{Authors' contributions}

$\mathrm{MB}$ was responsible for the $2^{\text {nd }}$ Belgian study, as well as drafting the manuscript. FD was responsible for the French data and made an important contribution to the analysis and interpretation of data. NM was responsible for the collection of all data and was involved in the analysis and interpretation. AV was responsible for one Belgian center (Cliniques Ste Elisabeth) and was involved in revising the manuscript. PP performed the statistical analysis. HR was the principal investigator of the PACS 01 study and was involved in revising the content of the manuscript. JD was involved in the initial drafting and revision of the manuscript. MS was involved in the design of the PACS 01 study and critically revising the manuscript. JK made an important contribution to the analysis and interpretation of data. JPM was involved in drafting and critically revising the manuscript.

All authors read and approved the final manuscript.

\section{Acknowledgements}

We wish to thank Magali Alsteen for her technical assistance and Mira Hryniuk for her support in linguistic revision of the manuscript.

\section{References}

I. Bines J, Oleske DM, Cobleigh MA: Ovarian function in premenopausal women treated with adjuvant chemotherapy for breast cancer. J Clin Oncol 1996, 14:1718-1729.

2. Valagussa P, Moliterni A, Zambetti M, Bonadonna G: Long-term sequelae from adjuvant chemotherapy: recent results. Cancer Res 1993, I 27:247-255.

3. Meirow D: Reproduction post-chemotherapy in young cancer patients. Mol Cel Endocrinol 2000, 169:123-131.

4. Vegetti W, Marozzi A, Manfredini E, Testa G, Alagna F, Nicolosi A, Caliari L, Taborelli M, Tibiletti MG, Dalpra L, Crosignani PJ: Premature ovarian failure. Mol Cell Endocrinol 2000, 161:53-57.

5. Padmanabhan N, Howell A, Rubens RD: Mechanism of action of adjuvant chemotherapy in early breast cancer. Lancet 1986, 2:4II-4I4.

6. Warne GL, Feirley KF, Hobbs JB, Martin FI: Cyclophosphamideinduced ovarian failure. New Engl J Med 1973, 289: I I59-II 62.

7. Goldhirsch A, Gelber RD, Castiglione M: The magnitude of endocrine effects of adjuvant chemotherapy for premenopausal breast cancer patients: the International Breast Cancer Study Group. Ann Onco 1990, I:183-188.

8. Hortobagyi GN, Buzdar AU, Marcus CE, Smith TL: Immediate and long-term toxicity of adjuvant chemotherapy regimens containing doxorubicin in trials at MD Anderson Hospital and Tumor Institute. J Natl Cancer Inst Monogr 1986, I: 105-109.

9. Levine MN, Brawell VH, Pritchard KI, Norris BD, Shepherd LE, AbuZahra H, Findlay B, Warr D, Bowman D, Myles J, Arnold A, Vandenberg T, Mackenzie R, Robert J, Ottaway J, Burnell M, Williams CK, Tu $D$ : Randomized trial of intensive cyclophosphamide, epirubicin and fluorouracil chemotherapy compared with cyclophosphamide, methotrexate and fluorouracil in premenopausal women with node-positive breast cancer. National Cancer Institute of Canada. Clinical Trial School. J Clin Oncol 1998, 16:265I-2658.

10. Roche H, Fumoleau P, Spielmann M, Canon JL, Delozier T, Serin D, Symann M, Kerbrat P, Soulié P, Eichler F, Viens P, Monnier A, Vinde- 
voghel A, Campone M, Goudier MJ, Bonneterre J, Ferrero JM, Martin AL, Geneve J, Asselain B: Sequential adjuvant epirubicin-based and docetaxel chemotherapy for node-positive breast cancer patients: the FNLCC PACS 0I trial. J Clin Oncol 2006, 24:5664-567I.

II. Fornier MN, Modi S, Panageas KS, Norton L, Hudis C: Incidence of chemotherapy-induced, long-term amenorrhea in patients with breast carcinoma aged $\mathbf{4 0}$ years and younger after adjuvant anthracycline and taxane. Cancer 2005, I04(8): I575-I579.

12. Davis L, Klitus M, Mintzer D: Chemotherapy-induced amenorrhea from adjuvant breast cancer treatment: the effect of the addition of taxanes. Clin Breast Cancer 2005, 6(5):42I-424.

13. Tham YL, Sixton K, Weiss H, Elledge R, Friedman L, Krame R: The rates of chemotherapy-induced amenorrhea in patients treatd with adjuvant doxorubicin and cyclophosphamide followed by taxane. Am J Clin Oncol 2007, 30:126-132.

14. Clemons $\mathrm{M}$, Simmons $\mathrm{Ch}$ : Identifying menopause in breast cancer patients: considerations and implications. Breast Cancer Res Treat 2007, 104:1 15-120.

15. Martin M, Pienkowski T, Mackey J, Pawlicki M, Guastalla JP, Weaver C, Tomiak E, Al-Tweigeri T, Chap L, Juhos E, Guevin R, Owell A, Fornander T, Hainsworth J, Coleman R, Vinholes J, Modiano M, Pinter T, Tang SC, Colwell B, Prady C, Provencher L, Walde D, Rodriguez-Lescure A, Hugh J, Loret C, Rupin M, Blitz S, Jacobs P, Murawsky M, Riva $A$, Vogel C: TAC improves disease-free survival and overall survival over FAC in node-positive early breast cancer patients, BCIRG 00I. SABCS 2003:abstract no 43.

16. Nabholtz JM, Pienkowski T, Mackey J, Pawlicki M, Guastalla JP, Vogel C, Weaver C, Walley B, Martin M, Chap L, Tomiak E, Juhos E, Guevin R, Howell A, Hainsworth J, Fornander T, Blitz S, Gazel S, Loret C, Riva A: Phase III trial comparing TAC (docetaxel, doxorubicin, cyclophosphamide) with FAC (5-fluorouracil, doxorubicin, cyclophosphamide) in the adjuvant treatment of node-positive breast cancer patients: interim analysis of the BCIRG 00I study. Proc Ann Meet Am Soc Clin Oncol 2002: I4I (abstract).

17. Ferretti G, Carlini P, Bria E, Felici A, Giannarelli D, Ciccarese M, Papaldo P, Fabi A, Cognetti F: Chemotherapy-induced amenorrhea in early breast cancer. Ann Oncol 2006, I7(2):352.

18. Abusief ME, Missmer SA, Ginsburg, Weeks JC, Wiener EP, Partridge $\mathrm{AH}$ : The effect of paclitaxel, dose density and trastuzumab in chemotherapy-related amenorrhea (CRA) in premenopausal women with breast cancer. San Antonio 2006:Abstract 2079.

19. Walshe JM, Denduluri N, Swain SM: Amenorrhea in premenopausal women after chemotherapy. J Clin Oncol 2006, 24:5769-5779.

20. Bonadonna G, Valagussa $P$, Moliterni A, Zambetti M, Brambilla C: Adjuvant cyclophosphamide, methotrexate, and fluorouracil in node-positive breast cancer. The results of 20 years of follow-up. N Engl J Med 1995, 332(6):901-906.

21. Parulekar WR, Day AG, Ottaway JA, Shepherd LE, Trudeau ME, Bramwell V, Levine M, Pritchard KI: Incidence and prognostic impact of amenorrhea during adjuvant therapy in high-risk premenopausal breast cancer: analysis of a National Cancer Institute of Canada Clinical Trials Group Study/NCIC CTG MA.5. J Clin Oncol 2005, 23:6002-6008.

22. Poikonen P, Saarto T, Elomaa I, Joensuu H, Blomqvist C: Prognostic effect of amenorrhea and elevated serum gonadotrophin levels induced by adjuvant chemotherapy in premenopausal node-positive breast cancer patients. Eur J Cancer 2000, 36:43-48.

23. Aebi S, Gelber S, Castiglione-Guertsh M, Gelber RD, Collins J, Thürlimann B, Rudenstam CM, Lindtner J, Crivellari D, Cortes-Funes $H$, Simoncini E, Werner ID, Coates AS, Goldhirsch A: Is chemotherapy alone adequate for young women with estrogen receptor-positive breast cancer? Lancet 2000, 355:|869-|874.

24. Del Mastro L, Venturini M, Sertoli MR, Rosso R: Amenorrhea induced by adjuvant chemotherapy in early breast cancer patients: prognostic role and clinical implications. Breast Cancer Res Treat 1997, 43:189-190.

25. Borde F, Chapelle-Marcilac I, Fumoleau P, Hery M, Roché H: Role of chemotherapy-induced amenorrhea in premenopausal node-positive operable breast cancer patients: 9-year followup results of French adjuvant study group. FASG data base. Breast Cancer Res Treat 2003 1982:S30.

26. Powles TJ: Prognostic impact of amenorrhea after adjuvant chemotherapy. Eur J Cancer 1998, 34:603-605.
27. Brincker H, Rose C, Rank F, Mouridsen HT, Jacobsen A, Dombernowsky P, Panduro J, Andersen KW: Evidence of a castrationmediated effect of adjuvant cytotoxic chemotherapy in premenopausal breast cancer. J Clin Oncol 1987, 5:177|-1778.

28. Vanhuyse M, Fournier C, Bonneterre J: Chemotherapy-induced amenorrhea influence on disease-free survival and overal survival in receptor-positive premenopausal early breast cancer patients. Ann Oncol 2005: I 283-1288.

29. Pagani O, O'Neill A, Castiglione M, Gelber RD, Goldhirsch A, Rudenstam CM, Lindtner J, Collins J, Crivellari D, Coates A, Cavalli F, Thürlimann B, Simoncini E, Fey M, Price K, Senn HJ: Prognostic impact of amenorrhea after adjuvant chemotherapy in premenopausal breast cancer patients with axillary node involvement: results of the International Breast Cancer Study Group (IBCSG) Trial VI. Eur J Cancer 1998, 34(5):632-640.

30. Cohen I, Figer A, Tepper R, Shapira J, Altaras MM, Yigael D, Beyth Y: Ovarian overstimulation and cystic formation in premenopausal tamoxifen exposure: comparison between tamoxifentreated and non-treated breast cancer patients. Gynecol Oncol 1998, 72:202-208.

31. Blumenfeld Z, Haim N: Prevention of gonadal damage during cytotoxic therapy. Ann Med 1997, 29:199-206.

32. Blumenfeld Z: Preservation of fertility and ovarian function and minimalization of chemotherapy-associated gonadotoxicity and premature ovarian failure: the role of inhibin-A and -B as markers. Mol Cell Endocrinol 2002, 187:93-105.

33. Rubens RD, Hayward JL, Knight RK, Bulbrook RD, Fentiman IS, Chaudary M, Howell A, Bush H, Crowther D, Sellwood RA, Georges WD, Howat JM: Controlled trial of adjuvant chemotherapy with melphalan for breast cancer. Lancet 1983, I:839-843.

\section{Pre-publication history}

The pre-publication history for this paper can be accessed here:

\section{http://www.biomedcentral.com/1471-2407/8/56/prepub}

Publish with BioMed Central and every scientist can read your work free of charge

"BioMed Central will be the most significant development for disseminating the results of biomedical research in our lifetime. "

Sir Paul Nurse, Cancer Research UK

Your research papers will be:

- available free of charge to the entire biomedical community

- peer reviewed and published immediately upon acceptance

- cited in PubMed and archived on PubMed Central

- yours - you keep the copyright

Submit your manuscript here:

http://www.biomedcentral.com/info/publishing_adv.asp
BioMedcentral 